\title{
CORRELATION BETWEEN BRAIN MAGNETIC RESONANCE CHANGES AND RESPONSE TO FUNCTIONALLY BASED REHABILITATION PROGRAM IN CHILDREN WITH SPASTIC CEREBRAL PALSY
}

By

\begin{abstract}
Abd El-Hamed Fikry Abd El-Aziz ${ }^{1}$, El-Sayed Mohammed Al-Nagar ${ }^{1}$, Abd El-Naby Biomy Mohammed ${ }^{2}$ and Hassan Mohammed Awwad ${ }^{3}$
\end{abstract}

Departments of ${ }^{1}$ Pediatrics, ${ }^{2}$ Diagnostic Radiology and ${ }^{3}$ Rheumatology, Physical Medicine and Rehabilitation, Faculty of Medicine, Al-Azhar University

Corresponding author: Abd El-Hamed Fikry Abd El-Aziz,

Mobile: (+20) 01128421706, E-mail: Abd-Elhamedfk@Yahoo.com

\begin{abstract}
Background: Cerebral palsy (CP) is the most common cause of physical disability in childhood with prevalence rates of 2-3 per 1000 live births in developed countries. CP is the leading cause of physical disability in children. Thus, neuroimaging is currently recommended as a standard evaluation in children with cerebral palsy.

Objective: To investigate the relationship and inter-relation between functional profiles including; gross motor function and manual ability, with brain magnetic resonance imaging characteristics in children with $\mathrm{CP}$ before and at end of functionally based exercise program.

Patients and Methods: This study was carried out on twenty five spastic CP children of both genders at age ranged from 3 months old to 12 years old, attending the out-patient pediatric clinic of Bab Al Sha'reya University Hospital, during the period from May 2019 to December 2019.

Results: Diplegia was the most common represented type, followed by quadriplegia and hemiplegia. The common causes were hypoxic ischemic encephalopathy (52\%), Post-kernicterus CP (32\%), and Post traumatic CP (16\%). History of mother drug intake, hypoxia, pre-mature birth, cyanosis and severe RDS, delivery with caesarian section, neonatal convulsion, jaundice and post-kernicterus complication, and head trauma were significantly associated with increased risk of CP.

Conclusion: History of mother drug intake, hypoxia, pre-mature birth, cyanosis and severe RDS, delivery with cesarian section, neonatal convulsion, jaundice and post-kernicterus complication, and head trauma were significantly associated with increased risk of CP. MRI scan was useful in revealing underlying brain abnormalities and speculating on the etiology of cerebral palsy.
\end{abstract}

Keywords: Brain Magnetic Resonance, Based Rehabilitation Program in Children, Spastic Cerebral Palsy.

\section{INTRODUCTION}

As a chronic condition, individuals with CP usually require lifetime medical, psychological, educational and social support. People with CP present with alterations in sensation, perception, cognition, communication and behavior that hinder activities of daily life, participation and quality of life (QOL) (García-Galant et al., 2020). 
The cause of CP is very diverse. The neuroanatomical findings on imaging also correlating with the clinical phenotype are also varied, and degrees of involvement range from mild to severe, all resulting in different clinical presentations. All of these factors contribute to children having different functional levels. Two children with similar CP phenotypes due to similar causes may then ultimately have different courses due to the additional role of personal and environmental factors and the interplay of other existing medical comorbidities (Schwabe, 2020).

A number of functional scales have been validated by multiple studies for $\mathrm{CP}$. They include Gross Motor Function Classification System (GMFCS), Manual Ability Classification System, Communication Function Classification System (CFCS) and Eating and Drinking Ability Classification System (EDAC). They are mainly used for predicting current and future management needs of children with $\mathrm{CP}$, and their use agrees with current thinking in management of CP (Ogoke, 2018). The functional classification remains the best classification of CP because it is a useful guide to providing care for patients appropriate for their functional level and helps clinicians set and discuss with parents/caregivers realistic rehabilitation goals (Bax et al., 2012).

The most widely-used test battery that measures the functional motor level in order to determine the motor development level of children with $\mathrm{CP}$ is the Gross Motor Function Measurement (GMFM). With GMFM, we can define the motor function level of the child; obtain aid in specifying the targets of the treatment, follow-up the post treatment development and present objective information regarding the child to relevant colleagues, other inter-discipliner professionals and families (Franki et al., 2020).

Neuroimaging, especially magnetic resonance imaging (MRI), contributes significantly to the understanding of the etiology and pathology of $\mathrm{CP}$, the timing of insults, and patients evaluations. Thus, categorizing patients with $\mathrm{CP}$ based on neuroradiologic findings were applied (Pakula et al., 2013).

Making a correlation between MRI brain finding and response to functionally based exercise program for spastic $\mathrm{CP}$ children would be a predictor of response to such a program in the future especially when comparing it with conventional physiotherapy (Franki et al., 2020).

This present study aimed to investigate the relationship and inter-relation between functional profiles including gross motor function and manual ability, with brain magnetic resonance imaging characteristics in children with $\mathrm{CP}$ before and at the end of functionally based exercise program.

\section{PATIENTS AND METHODS}

This study was carried out for spastic $\mathrm{CP}$ children attending the out-patient pediatric clinic of $\mathrm{Bab} \mathrm{Al}$ Sha'reya University hospital, during the period from May 2019 to December 2019.

\section{Inclusion criteria:}

Twenty five spastic $\mathrm{CP}$ children of both genders at age range from 3 months old to 12 years old. 


\section{Exclusion Criteria:}

1. Age of the patients more than 12 years and less than 3 months.

2. Any other type than spastic CP.

\section{All children were subjected to:}

1. Complete history taking including, prenatal, natal, and post-natal history, developmental history, vaccination, family history, relevant medical, surgical, trauma, and drugs used.

2. Clinical pediatric examination was performed stressing on neurological examination as related to our study.

3. All patients were examined by brain MRI and were classified functionally by GMFM and MAS.

4. Children were subjected to functionally based exercise program composed of circuit training of series exercises including aerobic and resistance exercises in every exercise session, of two weekly or at least three monthly schedules lasting for 6 to 8 months.

5. Using MRI scanning, investigate the relationship and inter-relation between functional profiles including; gross motor function and manual ability, with brain magnetic resonance imaging characteristics in children with $\mathrm{CP}$ before and at end of functionally based exercise program.

\section{Modified Ashworth Scale (MAS) instructions:}

General Information according to $R w$ and Smith (1987): Place the patient in a supine position. If testing a muscle that primarily flexes a joint, place the joint in a maximally flexed position and move to a position of maximal extension over one second (count "one thousand one"). If testing a muscle that primarily extends a joint, place the joint in a maximally extended position and move to a position of maximal flexion over one second (count "one thousand one").

\section{Scoring:}

- 0 No increase in muscle tone.

- 1 Slight increase in muscle tone, manifested by a catch and release or by minimal resistance at the end of the range of motion when the affected $\operatorname{part}(\mathrm{s})$ is moved in flexion or extension.

- 1+ Slight increase in muscle tone, manifested by a catch, followed by minimal resistance throughout the remainder (less than half) of the ROM.

- 2 More marked increase in muscle tone through most of the ROM, but affected part(s) easily moved.

- 3 Considerable increase in muscle tone, passive movement difficult.

- 4 Affected part(s) rigid in flexion or extension.

\section{Gross Motor Function Measure (GMFM):}

The GMFM is a standardized observational instrument designed and validated to measure change in gross motor function over time in children with cerebral palsy. The scoring key is meant to be a general guideline. However, most of the items have specific descriptors for each score. It is imperative that the guidelines contained in the manual be used for scoring each item. 


\section{ABD EL-HAMED FIKRY et al.,}

Scoring key:

- $0=$ does not initiate.

- $1=$ initiates.

- $2=$ partially completes.

- $3=$ completes.

- 9 (or leave blank) $=$ not tested (NT) [used for the GMAE-2 scoring*].

It is important to differentiate a true score of " 0 " (child does not initiate) from an item which is Not Tested (NT) if you are interested in using the GMFM-66 Ability Estimator (GMAE) Software.

\section{Statistical analysis:}

Data collected throughout history, basic clinical examination, laboratory investigations and outcome measures coded, entered and analyzed using Microsoft Excel software. Data were then imported into Statistical Package for the Social Sciences (SPSS version 22.0) software for analysis. According to the type of data qualitative represent as number and percentage, quantitative continues group represent by mean \pm SD. Wilcoxon Test Was Used, And Parried Test Was Used to compare before and after Treatment. Differences between parametric quantitative independent groups by $\mathrm{t}$ test. $\mathrm{P}$ value was set at $<0.05$ for significant results.

\section{RESULTS}

$64 \%$ of studied group were males with mean age of 3.8 years old. Commonest type of $\mathrm{CP}$ presented among studied group was diplegia among $48 \%$ of them and commonest cause was $52 \%$ hypoxic ischemic encephalopathy (Table 1).

Table (1): Basic characteristics of the studied population

\begin{tabular}{|c|c|c|}
\hline $\begin{array}{ll}\text { Studied group }(n=25) \\
\end{array}$ & $\mathbf{N}$ & $\%$ \\
\hline $\begin{array}{l}\text { Gender } \\
\text { Male } \\
\text { Female }\end{array}$ & $\begin{array}{c}16 \\
9\end{array}$ & $\begin{array}{l}64 \\
36\end{array}$ \\
\hline $\begin{array}{l}\text { Type of spastic CP } \\
\text { Hemiplegia } \\
\text { Diplegia } \\
\text { Quadriplegia }\end{array}$ & $\begin{array}{c}4 \\
12 \\
9\end{array}$ & $\begin{array}{l}16 \\
48 \\
36\end{array}$ \\
\hline $\begin{array}{l}\text { Cause of CP } \\
\text { Post-kernicterus } \\
\text { Hypoxic ischemic encephalopathy } \\
\text { Post-traumatic }\end{array}$ & $\begin{array}{c}8 \\
13 \\
4\end{array}$ & $\begin{array}{l}32 \\
52 \\
16\end{array}$ \\
\hline & \multicolumn{2}{|c|}{ Mean \pm SD } \\
\hline Age (years) & \multicolumn{2}{|c|}{$\begin{array}{l}3.8 \pm 2.5 \\
1-9\end{array}$} \\
\hline
\end{tabular}

There was a statistical significant difference in both reading of Aschor scale before and after GMFM regarding upper and lower limbs results, while change in trunk reading after GMFM not reach significant level (Table 2). 
Table (2): Difference in Aschor scale before and after GMFM among the studied population (Mean \pm SD)

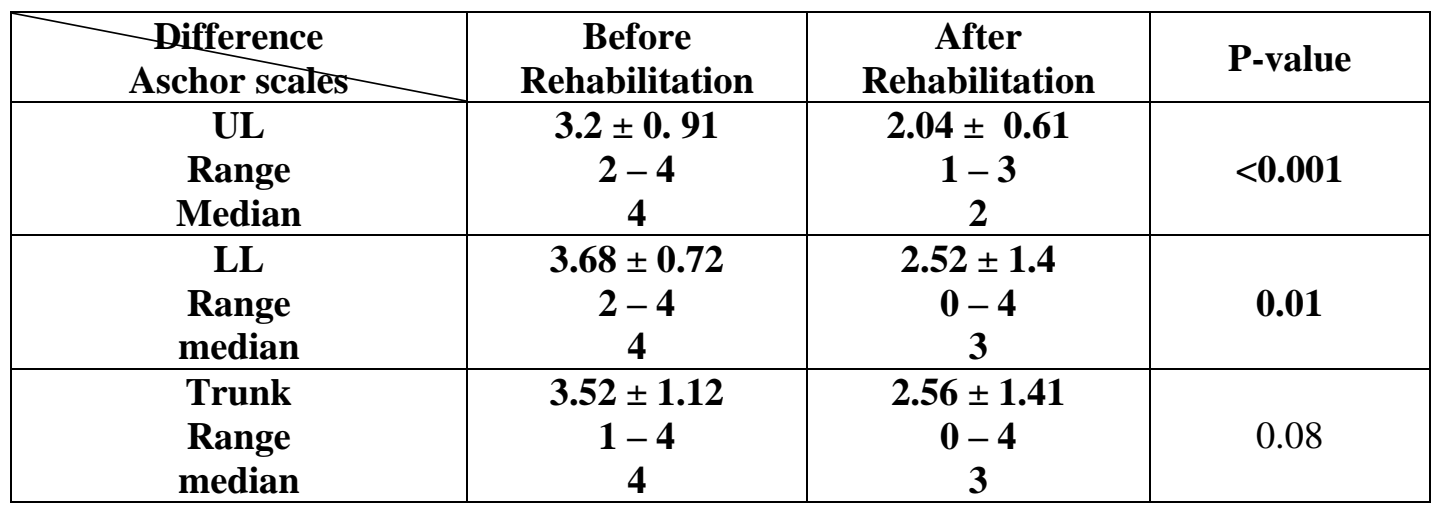

There was a statistical significant difference in percentages of two results of
GMFM regarding total score and lying and rolling item (Table 3).

Table (3): GMFM among the studied population (Mean \pm SD)

\begin{tabular}{|c|c|c|c|}
\hline Difference & $\begin{array}{c}\text { Before } \\
\text { GMFM }\end{array}$ & $\begin{array}{c}\text { After } \\
\text { Rehabilitation }\end{array}$ & $\begin{array}{c}\text { P- } \\
\text { value }\end{array}$ \\
\hline Lying \& rolling (\%) & $\mathbf{5 . 9} \pm \mathbf{4 . 2}$ & $\mathbf{7 2 \pm 1 4 . 9 6}$ & \\
Range & $\mathbf{2 - 9 . 8}$ & $\mathbf{5 8}-\mathbf{8 6}$ & $\mathbf{0 . 0 1}$ \\
Median & $\mathbf{5 . 9}$ & $\mathbf{7 2}$ & \\
\hline Sitting & $18.2 \pm 25.1$ & $63.7 \pm 44.8$ & \\
Range & $0-60$ & $0-100$ & $<0.001$ \\
Median & 1.7 & 100 & \\
\hline Crawling \& kneeling & $13.8 \pm 25.3$ & $49.2 \pm 48.5$ & \\
Range & $0-69$ & $0-100$ & 0.001 \\
Median & 0 & 86 & \\
Standing & $10.1 \pm 13.9$ & $48 \pm 47.6$ & \\
Range & $0-30.8$ & $0-100$ & 0.001 \\
Median & 0 & 80 & \\
\hline Range & $3.38 \pm 5.1$ & $38.6 \pm 40.3$ & \\
Median & $0-12.5$ & $0-100$ & 0.001 \\
Total $(\%)$ & 0 & 52.8 & \\
Range & $\mathbf{1 5 . 6 \pm 1 9 . 5}$ & $\mathbf{6 0 . 7} \pm \mathbf{4 1 . 9}$ & \\
Median & $\mathbf{0}-\mathbf{4 8}$ & $\mathbf{2}-\mathbf{1 0 0}$ & $<\mathbf{0 . 0 0 1}$ \\
\hline
\end{tabular}

$68 \%$ of studied patients presented with abnormal MRI changes, commonly peripheral brain atrophy among $29.4 \%$ of them (Table 4). 
Table (4): MRI changes among the studied population

\begin{tabular}{|l|c|c|}
\hline \multicolumn{1}{|c|}{ Studied group } & N & $\%$ \\
Variables & & \\
\hline MRI before GMFM & $\mathbf{8}$ & $\mathbf{3 2}$ \\
Normal for age & $\mathbf{1 7}$ & $\mathbf{6 8}$ \\
Abnormal CNS insult & $(\mathbf{n = 1 7})$ & \\
\hline Type of MRI change: & $\mathbf{4}$ & $\mathbf{2 3 . 5}$ \\
Post hypoxic insult & $\mathbf{5}$ & $\mathbf{2 9 . 4}$ \\
Peripheral brain atrophy & $\mathbf{4}$ & $\mathbf{2 3 . 5}$ \\
Post cerebellar arachnoid cyst & $\mathbf{2 3 . 5}$ \\
Impressive of lissencefhaly type 1 & $\mathbf{2 5}$ & $\mathbf{1 0 0}$ \\
\hline MRI after GMFM & & \\
No change & & \\
\hline
\end{tabular}

\section{DISCUSSION}

Twenty five spastic CP children of both genders at age range from (3 month old to 12 years old), were attending the out-patient pediatric clinic of $\mathrm{Bab} \mathrm{Al}$ Sha'reya University Hospital. All children were subjected to complete history followed by clinical examination with special attention for neurological assessment. Finally, all children were examined by brain MRI and classified according to GMFM classification. Children were subjected to functionally based exercise program composed of circuit training of series exercises including aerobic and resistance exercises in every exercise session, of two weekly or at least three monthly schedules lasting for 6 to 8 months.

An epidemiological data in the current study of patients with $\mathrm{CP}$ determines the demographical, risk factors as well as clinical features of patients with $\mathrm{CP}$. The current study showed that $64 \%$ and $36 \%$ of studied group were males and female, respectively, with no significant difference in age between different groups, with 1.7:1 male to female ratio. Similar results were reported (Pinto et al.,
2016; Choi et al., 2018 and Hawe et al., 2020). In accordance, high prevalence rates in boys compared to girls were reported. Philip et al. (2020) documented that gender distribution was $52.1 \%$ male and $48 \%$ female. Also, Kundu et al. (2020) found that males were more affected than females $(67.7 \%$ boys and $30.3 \%$ girls) with male to female ratio 2.09: 1, which might be conducted to the male sex hormones and difference in brain development between two genders. In contrary, Soleymani et al. (2010) reported that female prevalence was higher than male $(52.7 \%$ and $47.3 \%$, respectively).

Regarding types of cerebral palsy in the current study, diplegia was $(48 \%)$, the most common represented type, followed by quadriplegia and hemiplegia ( $(36 \%$ and $16 \%$, respectively). Previously reported distributions of motor subtypes within large CP populations have been highly variable, with hemiplegia, diplegia, quadriplegia, and other $\mathrm{CP}$ subtypes reported by Goel and Ojha (2015), Pinto et al. (2016) and Philip et al. (2020). Kundu et al. (2020) reported that most cases were $53.3 \%$ quadriplegic type, $20.7 \%$ hemiplegic, $10 \%$ diplegic. On the other hand, Springer et al. (2019) found 
that the distribution of $\mathrm{CP}$ types were $37.2 \%$ Hemiplegia, $19.9 \%$ diplegia, $30.4 \%$ tri/quadriplegia, $1.72 \%$ ataxic, $10.8 \%$ dyskinetic. Ara et al. (2018) documented that diplegia, quadriplegia and hemiplegia were $8.6 \%, 71.4 \%$ and $11.4 \%$, respectively. However, Hou et al. (2014) noticed that spastic diplegia was the main type in preterm infants while hemiplegia and ataxia were mainly seen in term infants (Hou et al., 2014).

The major known etiological risk factors for $\mathrm{CP}$ were bleeding and threatened miscarriages in prenatal period, birth asphyxia, premature baby and low birth weight in the perinatal period, convulsions, and hyperbilirubinemia in the postnatal period (Ogoke, 2018). Whatever, presence of any of these conditions, it does not mean this will result in $\mathrm{CP}$, rather it means higher prevalence of CP (Rana et al., 2017).

However, the common causes were observed in the current study were $(52 \%)$ hypoxic ischemic encephalopathy, followed by (32\%) Post-kernicterus CP and (16\%) Post traumatic CP. However, relatively little data are available on the etiology of CP especially in low- and middle-income countries (LMIC). The limited data available suggest that $\mathrm{CP}$ in these countries is less often caused by complications associated with preterm birth than in western industrialized countries, and more often by asphyxia and hyperbilirubinemia at term, and by postnatal infections, such as meningitis (Hadders-Algra, 2014).

Prenatal, natal and post-natal risk factors for $\mathrm{CP}$ in the current study were been. As demonstrated in the results, history of mother drug intake, hypoxia, pre-mature birth, cyanosis and sever RDS, delivery with caesarian section, neonatal convulsion, jaundice and post-kernicterus complication, and head trauma were significantly associated with increased risk of $\mathrm{CP}$. Comparable results were reported by Soleymani et al. (2010), who reported that neonatal convulsion and postnatal epilepsy, preterm delivery and maternal drug intake during pregnancy were significantly associated with CP.

The current study showed a statistical significant difference in percentages of results of GMFM between beginning and at end of program, regarding total score and lying and rolling item (high significant and significant, respectively).

The majority of research into the effectiveness of rehabilitation and the mechanisms that underlie responses to therapy has been conducted with schoolaged children with $\mathrm{CP}$, but major brain growth and development occurs in the first 2 years of life. This period could represent a critical window during which rehabilitation might be most effective (Reid et al., 2015). Such critical periods of development might primarily reflect time windows during which abnormal neural organization can be prevented, rather than periods during which the brain is simply more able to repair existing damage. One pilot study $(\mathrm{n}=5)$ of lower limb rehabilitation has indicated that intense rehabilitation is feasible and effective in children with $\mathrm{CP}$ aged $<2$ years, and a follow-up clinical trial is in progress (Eyre, 2013).

In previous studies significant associations between gross motor function and manual ability were demonstrated (Hidecker et al., 2012, Himmelmann et 
al., 2013 and Compagnone et al., 2014). In the current study, results showed a statistical significant difference in both reading of MAS before and after GMFM program regarding upper and lower limbs results, while change in trunk reading after GMFM not reach significant level. Different responses were reported previously. Theis et al. (2015) and Kalkman et al. (2018) reported acute response to stretching, It was hypothesized that would be explained by the increase in fascicle strain. In contrary, Hösl et al. (2018) reported low response. However, the effectiveness of stretchingbased interventions for improving function is poor. This may be due to the behavior of a spastic muscle during stretch, which is poorly understood (Kalkman et al., 2020).

That response might be explained by different theories. The neurological lesion in $\mathrm{CP}$ causes adaptations in the muscle, including muscle atrophy, fibrosis, muscle shortening and overstretched sarcomeres. Additionally, there is a lack of muscle growth (Willerslev-Olsen et al., 2018). This dynamic shortening of the muscles is typically treated with stretching exercises, botulinum toxin injections, casting or ankle-foot-orthoses (Kalkman et al., 2020). In children with $\mathrm{CP}$ this is additionally complicated by the fact that growth factor seems to be further altered from typical (Von Walden et al., 2018 and Pingel et al., 2019). Thus, stretching exercises, there is limited evidence to support functional improvements (Katalinic et al., 2011, Harvey et al., 2017 and Kalkman et al., 2020).

Brain imaging methodologies particularly Magnetic Resonance Imaging
(MRI) have been employed to understand the micro and microstructural changes in the brain structure and function in $\mathrm{CP}$ patients (Ouyang et al., 2019). The brain lesions on MRI are classified as brain mal-developments, periventricular white matter lesions (PWML), grey matter lesions or post-natal lesions (Philip et al., 2020).

In the current study, abnormal MRI scans were reported in $68 \%$ of studied subjects, which classified into (52.9\%) grey matter lesions; peripheral brain atrophy and post hypoxic insult $(29.4 \%$ and $23.5 \%$, respectively), in addition to (47.1\%) brain mal-developments; impressive of lissencefhaly type 1 , and post cerebellar arachnoid cyst $(23.5 \%$, each).

MRI imaging abnormalities were reported in different studies. Philip et al. (2020) reported that in 796 cases $97.6 \%$ showing abnormalities on MRI. Also, Springer et al. (2019) and Kundu et al. (2020) reported that total $94.4 \%$ and $84.7 \%$, respectively, had documented abnormal MRI.

Normal MRI findings were reported in different studies (van Genderen et al., 2012 and Qin et al., 2018). In the current study, normal MRI scans were detected among $32 \%$ of studied subjects. However, lower rate were reported by $(15 \%)$ Reid et al. (2014), (12\%) Arnfield et al. (2013), (10.4\%) Yim et al. (2017) and (5.6\%) Springer et al. (2019).

There are specific situations where one would expect a normal MRI; causal mechanisms that are sub-structural are one of them. Another one would be genetic or metabolic conditions. Although genetic causes of $\mathrm{CP}$ were previously thought to 
be uncommon, this notion is being challenged by multiple studies suggesting that there might be a stronger genetic link than was previously postulated (Springer et al., 2019). Also, Leonard et al. (2011) and Benini et al. (2013) suggested that the limitations of contemporary imaging may be part of the explanation. Franki et al. (2020) concluded that the quality of the certain type of MRI may have been higher scan quality compared to less recent types.

Among neuroimaging studies, brain magnetic resonance imaging (MRI) is regarded as the most suitable tool to visualize brain lesion and to obtain insight into the functional outcomes of patient with CP (Himmelmann et al., 2013). Several researches reported significant improvement of motor function after interventions (Kakuda et al., 2012 and Ueda et al., 2020). Mailleux et al. (2020) reported that global classification scales (i.e. GMFM, MAS) were related with MRI.

MRI changes in the current study after GMFM were not detected. Absence of MRI changes and its correlation with measures of clinical improvement suggested possible mechanisms underlying these changes (Wu et al., 2020).

Studies examining structure-function relationships in children with $\mathrm{CP}$ were limited (Wang et al., 2014, Arrigoni et al., 2016 and Meyns et al., 2016). However, structure function relationships cannot be thoroughly investigated using such conventional MRI measures (Mailleux et al., 2020). The use of more sensitive measures of function, such as robotics, might aid in detecting more subtle changes in function and as such allow for a better discrimination between the children. Diffusion tensor imaging, magnetic resonance spectroscopy, functional magnetic resonance imaging and fast spin echo imaging have improved greatly the possibility of a comprehensive radiologic changes (Pakula et al., 2013). Therefore, It was difficult to identify a clear relationship between brain structural changes on MRI with different motor type of CP (Philip et al., 2020).

Wu et al. (2020) hypothesized that after comprehensive treatments patients would develop regional and network topological alterations involving typical motor regions, as well as sensory/atypical regions; and these alterations in neural activities would correlate to clinical motor function scores.

\section{CONCLUSION}

History of mother drug intake, hypoxia, pre-mature birth, cyanosis and sever RDS, delivery with caesarian section, neonatal convulsion, jaundice and post-kernicterus complication, and head trauma were significantly associated with increased risk of CP. MRI scan was useful in revealing underlying brain abnormalities and speculating on the etiology of cerebral palsy.

There were associations between neuroimaging findings and neurological subtype and CP severity (i.e. GMFM Level). These observed associations may improve our understanding of the pathogenesis and etiology of $\mathrm{CP}$ and provide clinicians and families with information to aid in management of $\mathrm{CP}$.

\section{REFERENCES}

1. Ara R, Islam M, Rahman M, Begum M, Jahan F, Hosneara M, Farzana M, Islam 
M, Ara R and Bhuiyan M. (2018): Magnetic Resonance Imaging of Cerebral Palsy in the Assessment of Time of Brain Insult. Mymensingh Medical Journal, 27(3): 453-60.

2. Arnfield E, Guzzetta A and Boyd R (2013): Relationship between brain structure on magnetic resonance imaging and motor outcomes in children with cerebral palsy: a systematic review. Research in Developmental Disabilities, 34(7): 2234-2250.

3. Arrigoni FD, Peruzzo C, Gagliardi C, Maghini P, Colombo FS, Iammarrone C, Pierpaoli F and Turconi AC. (2016): Wholebrain DTI assessment of white matter damage in children with bilateral cerebral palsy: evidence of involvement beyond the primary target of the anoxic insult. American Journal of Neuroradiology, 37(7): 1347-1353.

4. Bax M, Tydeman $\mathrm{C}$ and Flodmark $O$. (2012): Clinical and MRI correlates of cerebral palsy: the European Cerebral Palsy Study. JAMA, 296(13): 1602-1608.

5. Benini R, Dagenais L, Shevell MI and Consortium Q. (2013): Normal imaging in patients with cerebral palsy: what does it tell us? The Journal of Pediatrics, 162(2): 369 374. e361.

6. Choi JY, Park J, Choi YS, Goh Y and Park ES. (2018): Functional communication profiles in children with cerebral palsy in relation to gross motor function and manual and intellectual ability. Yonsei Medical Journal, 59(5): 677-685.

7. Compagnone E, Maniglio J, Camposeo S, Vespino T, Losito L, De Rinaldis M, Gennaro $L$ and Trabacca A. (2014): Functional classifications for cerebral palsy: correlations between the gross motor function classification system (GMFCS):, the manual ability classification system (MACS): and the communication function classification system (CFCS). Research in Developmental Disabilities, 35(11): 2651-2657.

8. Eyre J. (2013): Corticospinal tract development and its plasticity after perinatal injury. Neuroscience \& Biobehavioral Reviews, 31(8): 1136-1149.
9. Franki I, Mailleux L, Emsell L, Peedima ML, Fehrenbach A, Feys $\mathbf{H}$ and Ortibus E. (2020): The relationship between neuroimaging and motor outcome in children with cerebral palsy: A systematic review-Part A. Structural imaging. Research in Developmental Disabilities, 100: 1036-42.

10. García-Galant $M$, Blasco $M$, Reid $L$, Pannek K, Leiva D, Laporta-Hoyos O, Ballester-Plané J, Miralbell J, Caldú $X$ and Alonso X. (2020): Study protocol of a randomized controlled trial of home-based computerized executive function training for children with cerebral palsy. BMC Pediatrics, 20(1): 1-9.

11. Goel S and Ojha N. (2015): Trends of cerebral palsy in Rajasthan, India. Int $\mathbf{J}$ Adv Ayurveda Yoga Unani Siddha Homeopath, 4: 275-281.

12. Hadders-Algra, M, (2014): Early diagnosis and early intervention in cerebral palsy. Frontiers in Neurology, 5: 1-14.

13. Hawe RL, Kuczynski AM, Kirton A and Dukelow SP. (2020): Assessment of bilateral motor skills and visuospatial attention in children with perinatal stroke using a robotic object hitting task. Journal of Neuro Engineering and Rehabilitation, 17(1): 1-12.

14. Hidecker MJC, Ho NT, Dodge N, Hurvitz EA, Slaughter J, Workinger MS, Kent RD, Rosenbaum P, Lenski $M$ and Messaros BM. (2012): Inter- relationships of functional status in cerebral palsy: analyzing gross motor function, manual ability, and communication function classification systems in children. Developmental Medicine \& Child Neurology, 54(8): 737-742.

15. Himmelmann $K$, Lindh $K$ and Hidecker MJC. (2013): Communication ability in cerebral palsy: a study from the $\mathrm{CP}$ register of western Sweden. European Journal of Paediatric Neurology, 17(6): 568-574.

16. Hösl M, Böhm H, Eck J, Döderlein $L$ and Arampatzis A. (2018): Effects of backwarddownhill treadmill training versus manual static plantarflexor stretching on muscle-joint pathology and function in children with 
spastic Cerebral Palsy. Gait \& Posture, 65: 121-128.

17. Hou M, Fan X, Li Y, Yu R and Guo $H$. (2014): Magnetic resonance imaging findings in children with cerebral palsy. Zhonghua er ke za zhi= Chinese Journal of Pediatrics, 42(2):1-14.

18. Kakuda W, Abo M, Shimizu M, Sasanuma J, Okamoto T, Yokoi A, Taguchi K, Mitani S, Harashima $H$ and Urushidani N. (2012): A multi-center study on low-frequency rTMS combined with intensive occupational therapy for upper limb hemiparesis in post-stroke patients. Journal of Neuroengineering and Rehabilitation, 9(1): 4-9.

19. Kalkman BM, Bar-On L, O'Brien TD and Maganaris C. (2020): Stretching interventions in children with Cerebral Palsy: Why are they ineffective in improving muscle function and how can we better their outcome? Frontiers in Physiology, 11: 131-138.

20. Kalkman BM, Bar- On L, Cenni F, Maganaris CN, Bass A, Holmes G, Desloovere K, Barton GJ and O'Brien TD. (2018): Medial gastrocnemius muscle stiffness cannot explain the increased ankle joint range of motion following passive stretching in children with cerebral palsy. Experimental Physiology, 103(3): 350-357.

21. Katalinic OM, Harvey LA and Herbert RD. (2011): Effectiveness of stretch for the treatment and prevention of contractures in people with neurological conditions: a systematic review. Physical Therapy, 91(1): 11-24.

22. Kundu G, Ahmed S, Akhter $S$ and Islam $S$. (2020): Neuro-Imaging Changes in Cerebral Palsy: A Cross Sectional Study. Mymensingh Medical Journal, 29(1): 121-126.

23. Leonard JM, Cozens AL, Reid SM, Fahey MC, Ditchfield MR and Reddihough DS. (2011): Should children with cerebral palsy and normal imaging undergo testing for inherited metabolic disorders? Developmental Medicine \& Child Neurology, 53(3): 226-232.

24. Mailleux L, Franki I, Emsell L, Peedima ML, Fehrenbach A, Feys $H$ and Ortibus E.
(2020): The relationship between neuroimaging and motor outcome in children with cerebral palsy: A systematic reviewPart B diffusion imaging and tractography. Research in Developmental Disabilities, 97: 1035-39.

25. Meyns P, Van Gestel L, Leunissen I, De Cock P, Sunaert S, Feys H, Duysens J, Desloovere $K$ and Ortibus E. (2016): Macrostructural and microstructural brain lesions relate to gait pathology in children with cerebral palsy. Neurorehabilitation and Neural Repair, 30(9): 817-833.

26. Ogoke C. (2018): Clinical Classification of Cerebral Palsy. Cerebral Palsy-Clinical and Therapeutic Aspects. Pbl Intech Open Publisher, 1-14.

27. Ouyang M, Dubois J, Yu Q, Mukherjee $\mathbf{P}$ and Huang H. (2019): Delineation of early brain development from fetuses to infants with diffusion MRI and beyond. Neuroimage, 185: 836-850.

28. Pakula AT, Braun KVN and YearginAllsopp M. (2013): Cerebral palsy: classification and epidemiology. Physical Medicine and Rehabilitation Clinics, 20(3): 425-452.

29. Philip SS, Guzzetta A, Chorna O, Gole G and Boyd RN. (2020): Relationship between brain structure and Cerebral Visual Impairment in children with Cerebral Palsy: A systematic review. Research in Developmental Disabilities, 99: 103-105.

30. Pingel J, Barber L, Andersen IT, Walden FV, Wong C, Døssing $\mathrm{S}$ and Nielsen JB. (2019): Systemic inflammatory markers in individuals with cerebral palsy. European Journal of Inflammation, 17: 205-208.

31. Pinto KS, Carvalho CG, Nakamoto $L$ and Nunes LG. (2016): The Sarah evaluation scale for children and adolescents with cerebral palsy: description and results. Brazilian journal of physical therapy. AHEAD, 20(3):267-274.

32. Qin Y, Li Y, Sun B, He H, Peng R, Zhang T, Li J, Luo C, Sun C and Yao D. (2018): Functional connectivity alterations in children 
with spastic and dyskinetic cerebral palsy. Neural plasticity, 2018:705-708.

33. Rana M, Upadhyay J, Rana A, Durgapal S and Jantwal A. (2017): A Systematic Review on Etiology, Epidemiology, and Treatment of Cerebral Palsy. International Journal of Nutrition, Pharmacology, Neurological Diseases, 7(4): 76-82.

34. Reid LB, Rose SE and Boyd RN. (2015): Rehabilitation and neuroplasticity in children with unilateral cerebral palsy. Nature Reviews Neurology, 11(7): 390-393.

35. Reid SM, Dagia CD, Ditchfield MR, Carlin JB and Reddihough DS. (2014): Population- based studies of brain imaging patterns in cerebral palsy. Developmental Medicine \& Child Neurology, 56(3): 222232.

36. Schwabe AL. (2020): Comprehensive Care in Cerebral Palsy. Physical Medicine and Rehabilitation Clinics, 31(1): 1-13.

37. Soleymani F, Vameghi R, Biglarian A and Daneshmand N., (2010): Risk factors associated with cerebral palsy in children born in eastern and northern districts of Tehran, Iranian Red Crescent Medical Journal, 12(4): 428-433.

38. Springer A, Holzinger SD, Andersen J, Buckley D, Fehlings D, Kirton A, Koclas L, Pigeon N, Van Rensburg E and Wood E. (2019): Profile of children with cerebral palsy spectrum disorder and a normal MRI study. Neurology, 93(1): 88-96.

39. Theis N, Korff $\mathbf{T}$ and Mohagheghi AA. (2015): Does long-term passive stretching alter muscle-tendon unit mechanics in children with spastic cerebral palsy? Clinical biomechanics, 30(10): 1071-1076.

40. Ueda R, Yamada N, Abo M, Ruwan PW and Senoo A. (2020): MRI evaluation of motor function recovery by rTMS and intensive occupational therapy and changes in the activity of motor cortex. International Journal of Neuroscience, 130(3): 309-317.
41. Van Genderen $M$, Dekker $M$, Pilon $F$ and Bals I. (2012): Diagnosing cerebral visual impairment in children with good visual acuity. Strabismus, 20(2): 78-83.

42. Von Walden F, Gantelius S, Liu C, Borgström H, Björk L, Gremark O, Stål P, Nader GA and Ponté N. (2018): Muscle contractures in patients with cerebral palsy and acquired brain injury are associated with extracellular matrix expansion, proinflammatory gene expression, and reduced rRNA synthesis. Muscle \& Nerve, 58(2): 277285.

43. Wang S, Fan GG, Xu $K$ and Wang C. (2014): Altered microstructural connectivity of the superior and middle cerebellar peduncles are related to motor dysfunction in children with diffuse periventricular leucomalacia born preterm: a DTI tractography study. European Journal of Radiology, 83(6): 997-1004.

44. Willerslev- Olsen M, Choe Lund M, Lorentzen J, Barber L, Kofoed- Hansen M and Nielsen JB. (2018): Impaired muscle growth precedes development of increased stiffness of the triceps surae musculotendinous unit in children with cerebral palsy. Developmental Medicine \& Child Neurology, 60(7): 672-679.

45. Wu Q, Yue Z, Ge Y, Ma D, Yin H, Zhao H, Liu G, Wang J, Dou W and Pan Y. (2020): Brain Functional Networks Study of Subacute Stroke Patients With Upper Limb Dysfunction After Comprehensive Rehabilitation Including BCI Training. Frontiers in Neurology, 10: 1419-1422.

46. Yim SY, Yang CY, Park JH, Kim MY, Shin YB, Kang EY, Lee ZI, Kwon BS, Chang JC and Kim SW. (2017): Korean database of cerebral palsy: a report on characteristics of cerebral palsy in South Korea. Annals of Rehabilitation Medicine, 41(4): 638-643. 


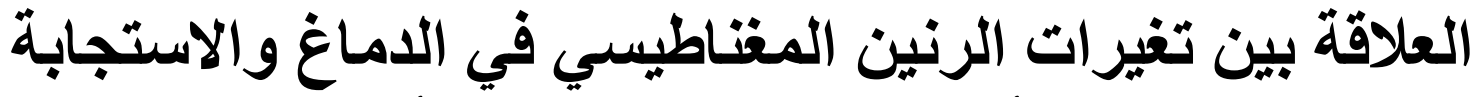

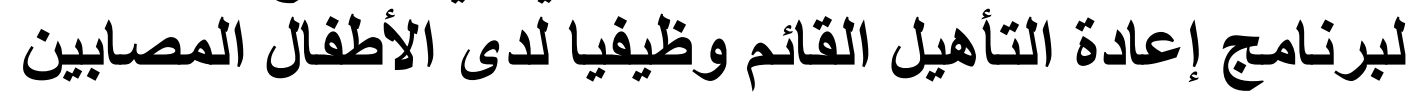

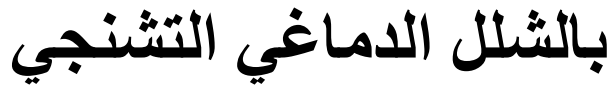

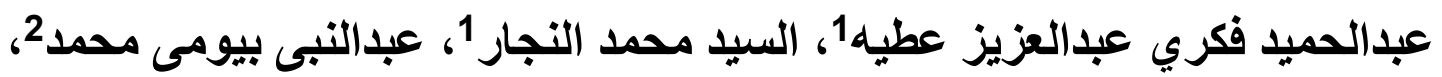
حسن محمدعواد3

أقسام 1طب الأطفال و2الأشعة التثخيصية و3|الروماتيزم والطب الفيزيائى وإعادة التأهيل كلية الطب، جامعة الأزهر

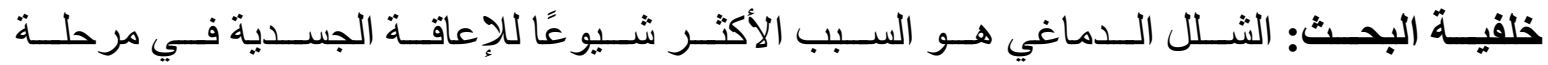

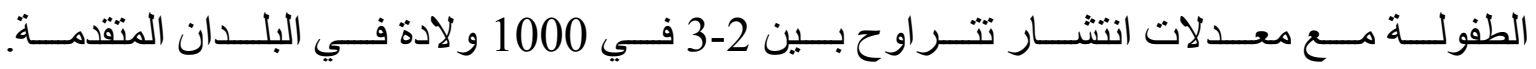

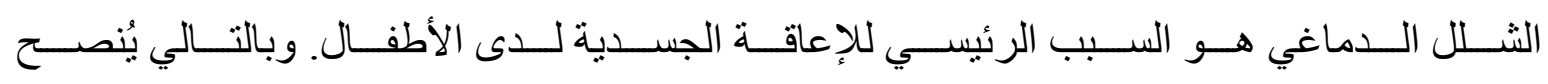
بالتصوير العصبي حاليًا كتقييم قياسي في الأطفال الهصابين بالثلل الدماغي. لإني.

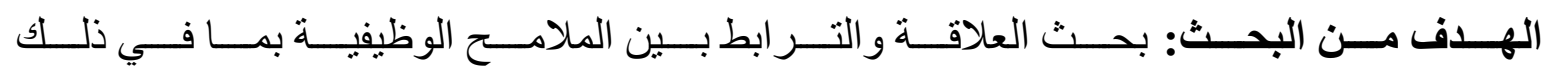

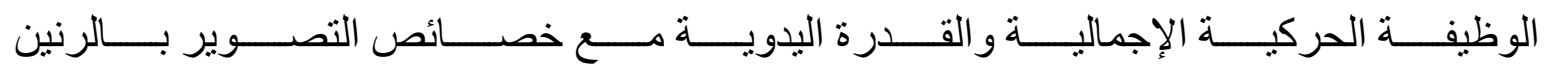

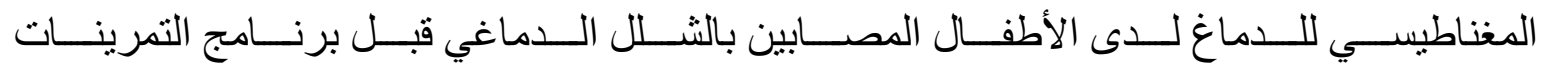

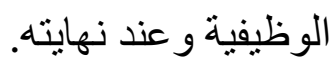

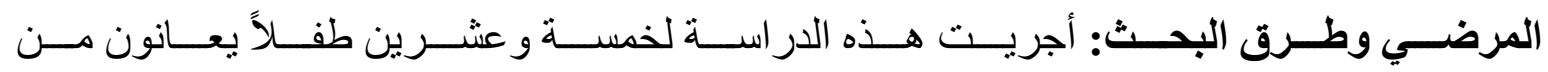

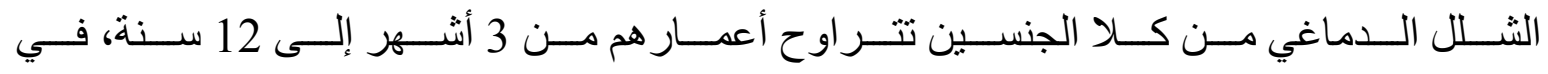

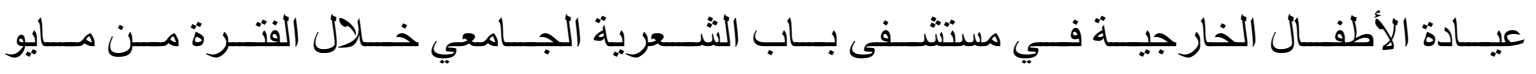
2019 حتى ديسمبر 2019.

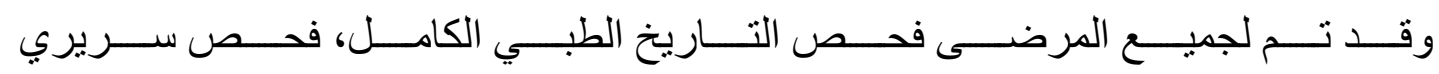

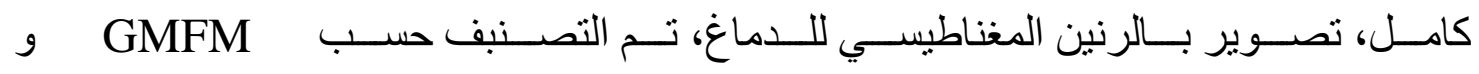

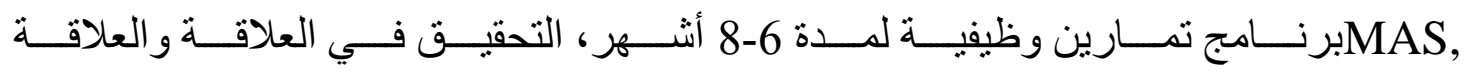

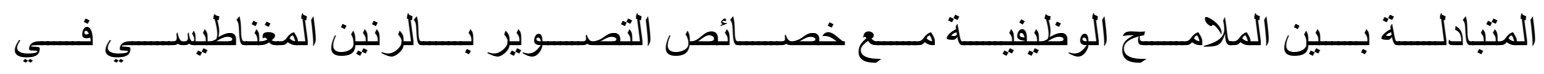

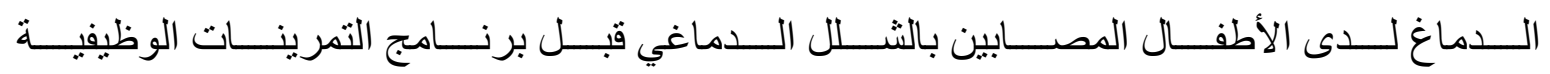

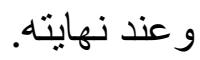




\section{ABD EL-HAMED FIKRY et al.,}

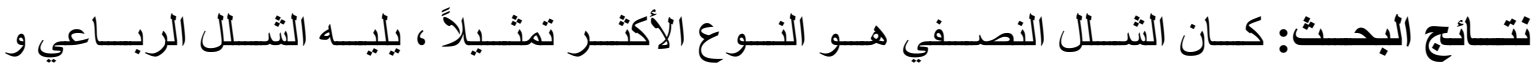

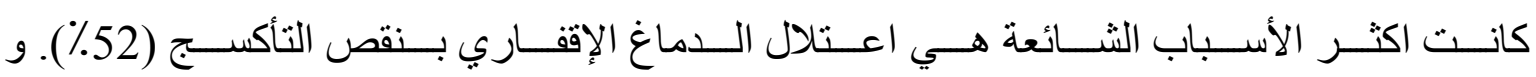

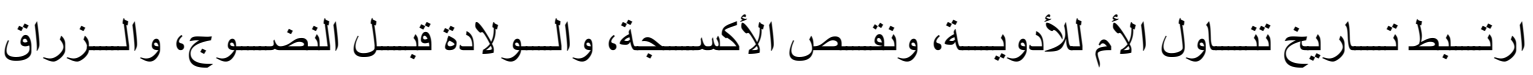

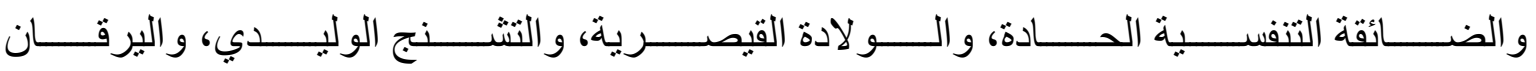

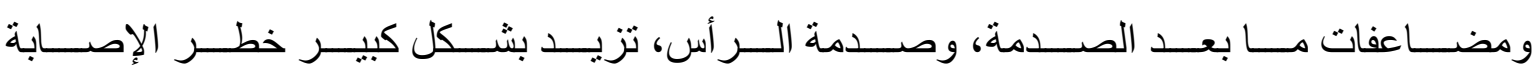

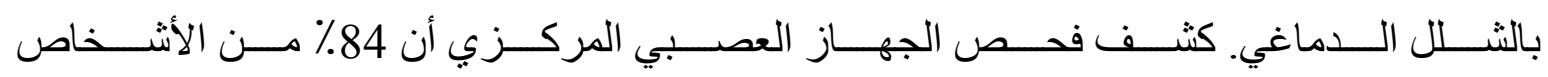

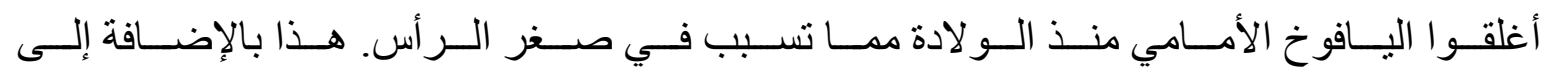

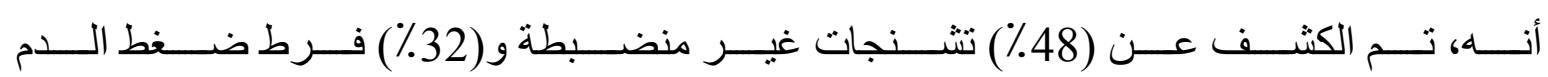

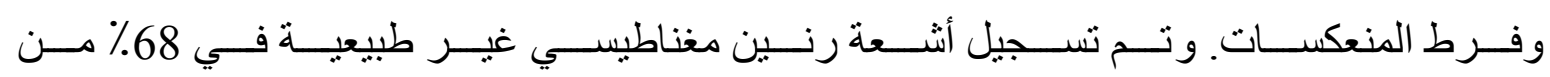

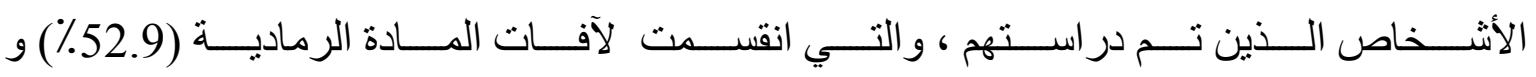

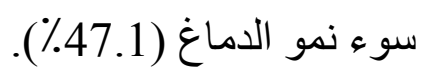

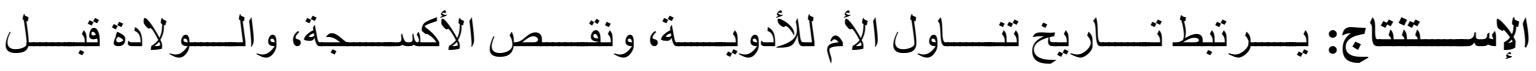

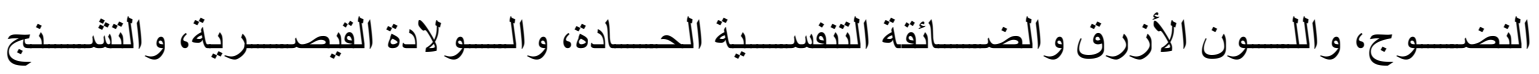

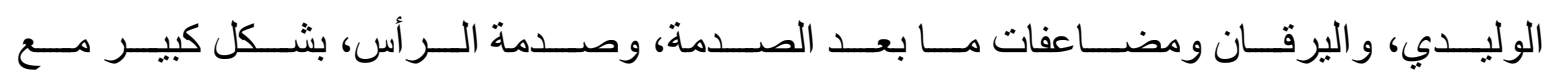

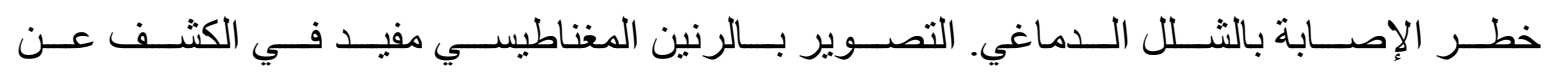

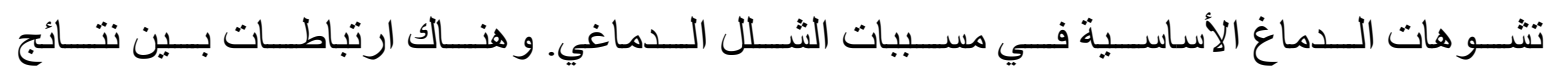

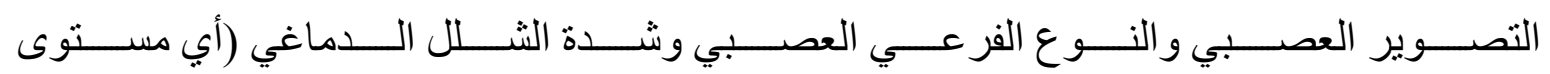

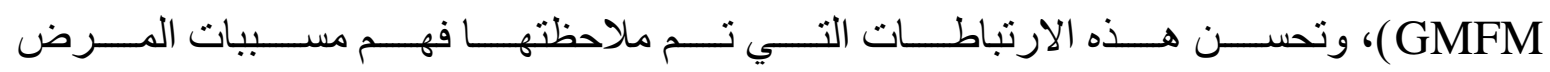

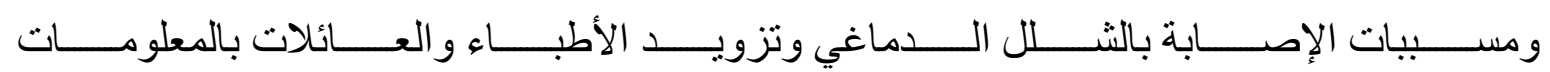
للمساعدة في إدارة الثلل الدماغي. 